\title{
Gene and microRNA analysis of neutrophils from patients with polycythemia vera and essential thrombocytosis: down-regulation of micro RNA-I and - 133 a
}

\author{
Stefanie Slezak ${ }^{1}$, Ping Jin1, Lorraine Caruccio1, Jiaqiang Ren ${ }^{1}$, \\ Michael Bennett ${ }^{2}$, Nausheen Zia1 ${ }^{1}$, Sharon Adams ${ }^{1}$, Ena Wang1, \\ Joao Ascensao $^{3}$, Geraldine Schechter ${ }^{3}$ and David Stroncek*1
}

\author{
Address: ${ }^{1}$ Department of Transfusion Medicine, Clinical Center, National Institutes of Health, Bethesda, Maryland, USA, ${ }^{2}$ Department of \\ Hematology, Emek Hospital, Afula, Israel and ${ }^{3}$ Hematology Section, Veterans Affairs Medical Center, Washington DC, USA \\ Email: Stefanie Slezak - stefanie.slezak@gmail.com; Ping Jin - pjin@cc.nih.gov; Lorraine Caruccio - lcaruccio@cc.nih.gov; \\ Jiaqiang Ren - renj@cc.nih.gov; Michael Bennett - benet_m@clalit.org.il; Nausheen Zia - zianau@sgu.edu; \\ Sharon Adams - sadams1@cc.nih.gov; Ena Wang - EWang@cc.nih.gov; Joao Ascensao - joao.ascensao@va.gov; \\ Geraldine Schechter - g.p.schechter@va.gov; David Stroncek* - dstroncek@cc.nih.gov \\ * Corresponding author
}

Published: 4 June 2009

Journal of Translational Medicine 2009, 7:39 doi:10.1 I86/1479-5876-7-39
Received: 17 March 2009

Accepted: 4 June 2009

This article is available from: http://www.translational-medicine.com/content/7/1/39

(c) 2009 Slezak et al; licensee BioMed Central Ltd.

This is an Open Access article distributed under the terms of the Creative Commons Attribution License (http://creativecommons.org/licenses/by/2.0), which permits unrestricted use, distribution, and reproduction in any medium, provided the original work is properly cited.

\begin{abstract}
Background: Since the V6I7F mutation in JAK2 may not be the initiating event in myeloprofilerative disorders (MPDs) we compared molecular changes in neutrophils from patients with polycythemia vera (PV) and essential thrombocythosis (ET), to neutrophils stimulated by GCSF administration and to normal unstimulated neutrophils
\end{abstract}

Methods: A gene expression oligonucleotide microarray with more than 35,000 probes and a microRNA (miR) expression array with 827 probes were used to assess neutrophils from 6 MPD patients; 4 with PV and 2 with ET, 5 healthy subjects and 6 healthy subjects given G-CSF. In addition, neutrophil antigen expression was analyzed by flow cytometry and 64 serum protein levels were analyzed by ELISA.

Results: Gene expression profiles of neutrophils from the MPD patients were similar but distinct from those of healthy subjects, either unstimulated or G-CSF-mobilized. The differentially expressed genes in MPD neutrophils were more likely to be in pathways involved with inflammation while those of G-CSF-mobilized neutrophils were more likely to belong to metabolic pathways. In MPD neutrophils the expression of CCRI was increased and that of several NF- $K B$ pathway genes were decreased. MicroRNA miR-I33a and miR-I in MPD neutrophils were down-regulated the most. Levels of II serum proteins were increased in MPD patients including MMP-I0, MMP-I3, VCAM, P-selectin, PDGF-BB and a CCRI ligand, MIP-I $\alpha$.

Conclusion: These studies showed differential expression of genes particularly involved in inflammatory pathways including the NF-kB pathway and down-regulation of miR-133a and miR-I. These two microRNAs have been previous associated with certain cancers as well as the regulation of hyperthrophy of cardiac and skeletal muscle cells. These changes may contribute to the clinical manifestations of the MPDs. 


\section{Introduction}

The chronic myeloproliferative disorders (MPDs) are clonal hematopoietic disorders that involve multiple cell lineages. They include polycythemia vera (PV), essential thrombocytosis (ET) and primary myelofibrosis (PMF) [1]. A mutation in the gene encoding Janus Kinase 2 (JAK2), which is involved with hematopoietic growth factor signaling, has been found in almost all patients with PV and about half those with ET [2-5]. This mutation, JAK2 V617F, is a gain of function mutation and hematopoietic progenitor cells from patients with this mutation have increased sensitivity to hematopoietic growth factors [5].

While JAK2 V617F has been found in neutrophils from many patients with chronic MPDs, it is not clear if JAK2 V617F is the initiating lesion in MPDs nor is the complete spectrum of the molecular changes associated with these disorders known. Germline JAK2 V617F mutations have not been found in familial MPD, however, somatic JAK2 V617F mutations have been identified in some affected kindreds $[6,7]$. Furthermore, first degree relatives of MPD patients have a 5- to 7-fold elevated risk of MPD, but the gene(s) or factors that predispose relatives to PV, ET and MF are not known [8]. This suggests that there are heritable alleles that predispose individuals to the acquisition of JAK2 V617F and the development of MPD [1,9]. Further characterization of the molecular changes in MPD neutrophils could lead to a better understanding of the development of these diseases and their clinical manifestations.

This study further characterized the molecular changes in neutrophils from patients with MPDs by comparing neutrophils from healthy subjects using global gene and microRNA (miR) expression arrays. The expression of neutrophil proteins was also assessed by flow cytometry and the levels of serum inflammatory factors by ELISA. Since G-CSF signals through JAK2 MPD neutrophils were also compared to those of healthy subjects after five days of G-CSF administration. In this way genes and miR could be identified whose change in expression was not due to constitutive activation by JAK2 V617F.

\section{Methods \\ Study Design}

These studies were approved by institutional review boards at the NIDDK, NIH and Veterans Administration Medical Center, Washington DC. Whole blood was collected into EDTA tubes from patients with MPD, healthy subjects, and healthy subjects given G-CSF. Neutrophils isolated from the EDTA blood was used for gene expression and microRNA analysis. For MPD patients whole blood was also collected into citrate tubes and was used to isolate neutrophils for JAK V617F analysis. Blood collected in tubes without anticoagulant was used to obtain serum for protein analysis. WHO criteria was used to make the diagnosis of PV and ET [10].

\section{G-CSF Mobilization of Granulocytes}

Healthy subjects were given 10 micrograms/kg of G-CSF (filgrastim, Amgen, Thousand Oaks, California, USA) subcutaneously daily for 5 days. Blood was collected for analysis approximately 2 hours after the last dose of GCSF was given.

\section{Neutrophil Isolation}

Whole blood, $6 \mathrm{~mL}$ in EDTA (K2 EDTA $1.8 \mathrm{mg} / \mathrm{mL}$, BD Vacutainer, Becton, Dickinson and Company, Franklin Lakes, NJ), was collected from healthy donors, MPD patients and donors following a course of G-CSF treatment. Percoll (Sigma, St. Louis, Missouri, USA) density gradients were used to isolate the neutrophils. Briefly, gradients were prepared by gently overlaying 63\% Percoll solution on top of $72 \%$ Percoll solution, in equal volumes. Prior to overlaying the whole blood sample on the gradient, the majority of red blood cells were removed via sedimentation by diluting whole blood 1:2 with hetastarch (Hespan; $6 \%$ heta starch in $0.9 \%$ sodium chloride, B. Braun Medical Inc., Irvine, California, USA) and incubating for approximately 20 minutes at room temperature. After layering the leukocyte rich/heta starch solution on the gradient, the sample was centrifuged at 1,500 rpm for 25 minutes with no brake upon centrifuge deceleration. The neutrophil layer was harvested from the interface between the two Percoll solutions and washed twice with physiologic saline.

\section{Flow cytometry for Surface Markers}

Flow cytometry analysis of granulocyte surface markers was performed on fresh whole blood samples. Cells were stained with monoclonal antibodies against CD177-FITC, CD15-FITC (Chemicon International, Temecula, CA), CD64-FITC, CD16-FITC, CD18-FITC, CD11b-FITC (Caltag Laboratories, Buckingham, UK) CD10-PE, CD31PE, CD44-FITC, CD45-FITC, CD55-FITC, CD59-FITC, CD62L-FITC (eBiosciences, San Diego, CA) and incubated at $4{ }^{\circ} \mathrm{C}$ for 30 minutes in the dark. Mouse IgG isotype controls were also used (Caltag Laboratories). The FACSCalibur flow cytometer and CellQuest Pro software (BD Biosciences, San Jose, CA) were used for analysis by acquiring 10,000 events and determining the viable neutrophil population by light scatter.

\section{Assessment of JAK2 V6I7F}

Isolated neutrophils were tested for JAK2 V617F by DNA sequencing. V617F mutations were identified utilizing sequence-based typing methodology. Primary amplification of the specific region of JAK2 utilized primers Jak2-1 $(p f)=$ tgc tga aag tag gag aaa gtg cat and Jak2-2 $(p r, s r)=$ tcc tac agt gtt ttc agt ttc aa which produced a 345bp prod- 
uct. After primary amplification, sequence primers $J a k 2-5$ $(s f)=$ agt ctt tct ttg aag cag caa and Jak2-2 $(p r, s r)=$ tcc tac agt gtt ttc agt ttc aa were utilized for detection of the V617F mutation. Conditions included the use of $2.0 \mathrm{mM}$ $\mathrm{Mg}++, 3$ pmole of primer, GeneAmp 10× PCR Gold Buffer, 0.35 unit of AmpliTaq gold DNA polymerase (ABI) $5 \mathrm{U} / \mathrm{ul}$, and $0.15 \mathrm{mM}$ each of $10 \mathrm{mM}$ dNTP mixture (Amersham) with Big Dye Terminator ${ }^{\boxplus}$ Cycle Sequencing kits (Applied Biosystems). Template DNA was utilized at a concentration of $40-60 \mathrm{ug} / \mathrm{mL}$. PCR cycling parameters were $95^{\circ} \mathrm{C}$ for 10 minutes; $95^{\circ} \mathrm{C}$ for 30 seconds $\rightarrow 52^{\circ} \mathrm{C}$ for 40 seconds $\rightarrow 72^{\circ} \mathrm{C}$ for 40 seconds $=40$ cycles; $72^{\circ} \mathrm{C}$ for 2 minutes and hold at $4^{\circ} \mathrm{C}$. Sequencing reactions were run on an Applied Biosystem 3730xL DNA Analyzer and analyzed utilizing standard alignment software.

\section{RNA Preparation, RNA Amplification and Labeling for Oligonucleotide Microarray}

Total RNA from harvested neutrophils was extracted using Trizol reagent according to the manufacturer's instructions (Invitrogen, Carlsbad, California, USA). The quality of secondary amplified RNA was tested with the Agilent Bioanalyzer 2000 (Agilent Technologies, Waldbronn, Germany) and amplified into antisense RNA (aRNA) as previously described [11]. Also total RNA from peripheral blood mononuclear cells pooled from six normal donors was extracted and amplified into aRNA to serve as the reference. Pooled reference and test aRNA were isolated and amplified in identical conditions to avoid possible interexperimental biases. Both reference and test aRNA were directly labeled using ULS aRNA Fluorescent Labeling kit (Kreatech, Amsterdam, The Netherlands) with Cy3 for reference and Cy5 for test samples. Whole-genome human $36 \mathrm{~K}$ oligonucleotide arrays were printed in the Infectious Disease and Immunogenetics Section of the Department of Transfusion Medicine, Clinical Center, NIH (Bethesda, Maryland, USA) using oligonucleotides purchased from Operon (Operon, Huntsville, Alabama, USA). The Operon Human Genome Array-Ready Oligo Set version 4.0 contains 35,035 oligonucleotide probes, representing approximately 25,100 unique genes and 39,600 transcripts excluding control oligonucleotides. The design is based on the Ensembl Human Database build (NCBI-35c) with full coverage on NCBI human Refseq dataset (04/04/2005). The microarray is composed of 48 blocks and one spot is printed per probe per slide. Hybridization was carried out in a water bath at $42^{\circ} \mathrm{C}$ for 18 to 24 hours and the arrays were then washed and scanned on a GenePix 4000 scanner at variable photomultiplier tube to obtain optimized signal intensities with minimum $(<1 \%$ spots) intensity saturation. The resulting data files were uploaded to the mAdb database http://nci array.nci.nih.gov and further analyzed using BRBArrayTools developed by the Biometric Research Branch,
National Cancer Institute http://linus.nci.nih.gov/BRBArrayTools.html.

\section{MicroRNAs Expression Profiling}

A microRNA probe set was designed using mature antisense microRNA sequences (Sanger data base, version 9.1) consisting of 827 unique microRNAs from human, mouse, rat and virus plus two control probes. The probes were $5^{\prime}$ amine modified and printed in duplicate on CodeLink activated slides (General Electric, GE Health, New Jersey, USA) via covalent bonding in the Immunogenetics Laboratory, DTM, CC, NIH. $4 \mu \mathrm{g}$ total RNA isolated by using Trizol reagent (Invitrogen, Carlsbad, California) was directly labeled with miRCURY ${ }^{\mathrm{TM}}$ LNA Array Power Labeling Kit (Exiqon, Woburn, Massachusetts, USA) according to manufacture's procedure. The total RNA from an Epstein-Barr virus (EBV)-transformed lymphoblastoid cell line was used as the reference for the microRNA expression array assay. The test sample was labeled with Hy5 and the reference with Hy3. After labeling, the sample and the reference were co-hybridized to the microRNA array at room temperature overnight in the presence of blocking reagents as previously described [12] and the slides were washed and scanned by GenePix scanner Pro 4.0 (Axon, Sunnyvale, California, USA). Resulting data files were uploaded to the mAdb database http://nci array.nci.nih.gov and further analyzed using BRBArrayTools developed by the Biometric Research Branch, National Cancer Institute http://linus.nci.nih.gov/BRBArrayTools.html.

\section{Array Data Processing}

For analysis of the gene and microRNA array data, the raw data set was filtered according to a standard procedure to exclude spots with minimum intensity that was arbitrarily set to an intensity parameter of 200 for gene expression data and 100 for microRNA array data in both fluorescence channels. Spots flagged by the analysis software and spots with diameters $<20 \mu \mathrm{m}$ for gene expression array and $<10 \mu \mathrm{m}$ for the microRNA array were excluded from the analysis.

The filtered data were normalized using median over entire array and were retrieved by the BRB ArrayTool http:/ /linus.nci.nih.gov/BRB-ArrayTools.html developed at the National Cancer Institute (NCI), Biometric Research Branch, Division of Cancer Treatment and Diagnosis. Hierarchical cluster analysis was conducted on the genes or microRNA using Cluster and TreeView software [13]. For annotation of genes and functional pathways, the Database for Annotation, Visualization and Integrated Discovery (DAVID) 2007 software http:// david.abcc.ncifcrf.gov/[14] and Ingenuity Pathway Analysis software http://www.ingenuity.com was used. All 
microRNA target prediction analysis used BRB ArrayTool microRNA targets program http://linus.nci.nih.gov/BRBArrayTools.html, TargetScan http://www.targetscan.org/ and miRBase Targets http://microrna.sanger.ac.uk.

\section{Gene and MicroRNA Expression Quantitative PCR}

To validate the microarray analysis, 5 genes and 2 microRNAs were selected for Quantitative PCR. Gene expressions for TNFAIP3 (Assay ID, Hs00234713_m1), NFKBIE (Assay ID, Hs00234431_m1), NFKBIA (Assay ID Hs00153283_m1), CBS (Assay ID Hs00163925_m1) and MCL1(Assay ID Hs03043899_m1) were quantified by TaqMan Gene Expression Assays (Applied Biosystems, Foster City, California, USA) according to manufacturers' protocol and normalized by GAPDH (Assay ID Hs99999905_m1) PCR amplification of target genes and quantification of the amount of PCR products were performed by ABI PRISM 7900 HT Sequence Detection System (Applied Biosystems). Differences in expression were determined by the relative quantification method; the $\mathrm{Ct}$ values of the test genes were normalized to the $\mathrm{Ct}$ values of endogenous control GAPDH. The fold change was calculated using the equation $2^{-\Delta \Delta \mathrm{Ct}}$.

Differentially expressed microRNAs, miR-133a (Assay ID, 4373142) and miR-219 (Assay ID, 4373080), were measured by TaqMan microRNA Assays (Applied Biosystems, Foster City, California, USA) as previously reported [15]. The differences of expression were determined by relative quantification method; the $\mathrm{Ct}$ values of microRNAs were normalized to the $\mathrm{Ct}$ values of endogenous control RNU48 (Assay ID 4373383). The fold change was calculated using the equation $2^{-\Delta \Delta \mathrm{Ct}}$.

\section{Analysis of Serum Proteins}

Serum samples were collected and frozen immediately, and stored at $-80^{\circ} \mathrm{C}$ until further analysis. The serum samples were analyzed by protein expression profiling. The level of 64 soluble factors were assessed on an ELISAbased platform (Pierce Search Light Proteome Array, Boston, MA) consisting of multiplexed assays that measured up to 16 proteins per well in standard 96 well plates (Table 1). The 64 factors were selected to included hematopoietic factors, factors associated with inflammation, and those previously found to be increased in the serum of healthy subjects given G-CSF [16].

\section{Statistical Analysis}

Unsupervised analysis was performed by using BRBArrayTools http://linus.nci.nih.gov/BRB-ArrayTools.html and the Stanford Cluster Program [17]. Class comparison analysis was performed using parametric unpaired Student's t-test to identify differentially expressed genes or microRNA among different sample groups and using different significance cutoff levels as demanded by the statistical power of each comparison. Statistical significance and adjustments for multiple test comparisons were based on univariate and multivariate permutation tests as previously described $[18,19]$.

\section{Results \\ Global Transcriptome Analysis}

Neutrophils from 6 MPD patients were studied; 4 with PV and 2 with ET. JAK2 V617F was detected in 3 of the 4 PV patients and in 1 of the 2 ET patients (Table 2). Global gene expression analyses of neutrophils from 6 subjects with MPDs were compared with 6 healthy subjects given 5 days of G-CSF and the 5 healthy subjects. Among the 17 samples and 35,000 probes in the array, 3,617 were expressed by $80 \%$ of the samples and their expression was increased by 2 -fold or greater in at least one sample. Unsupervised hierarchical clustering analysis of these 3,617 genes revealed three distinct groups: the G-CSF group which included 5 of the 6 G-CSF mobilized neutrophil samples, the MPD group with 4 of the 6 MPD neutrophil samples and 2 healthy subject neutrophils, and the mixed

Table I: Serum factors measured in MPD patients and healthy subjects

\begin{tabular}{|c|c|c|c|}
\hline$I L-I \alpha$ & MCP-I (CCL2) & TPO & $\mathrm{TNF} \alpha$ \\
\hline IL-I $\beta$ & MCP-2 (CCL8) & G-CSF & INF $\alpha$ \\
\hline IL-2 & MCP-3 (CCL7) & GM-CSF & $\mathrm{TGF} \alpha$ \\
\hline IL-6 & MCP-4 (CCLI3) & MMP-I & PDGFAA \\
\hline IL-IO & E-Selectin & MMP-2 & PDGFAB \\
\hline IL-II & P-Selectin & MMP-8 & PDGFBB \\
\hline IL-2R & L-Selectin & MMP-9 & HGF \\
\hline IL-4R & MIP-I $\alpha(C C L 3)$ & MMP-IO & VCAM \\
\hline IL-6R & MIP-I $\beta$ (CCL4) & MMP-I 3 & ICAM-I \\
\hline TARC (CCLI7) & MIP-I $\delta$ & TIMP-I & PECAM-I \\
\hline OPN & MIP-3 $\alpha(C C L 20)$ & TIMP-2 & FASL \\
\hline IP- 10 & MIP-3 $\beta$ (CCLI3) & MPO & CD40L \\
\hline Eotaxin (CCLII) & MIG (CXCL9) & SAA & RANK \\
\hline ITAC (CXCLII) & IP-IO (CXCLIO) & SDF-Ib (CXCLI2) & RANKL \\
\hline ENA-78 (CXCL5) & $\mathrm{GRO} \alpha(\mathrm{CXCLI})$ & OPG & RANTES (CCL5) \\
\hline Exodus II & GRO $\gamma(\mathrm{CXCL3})$ & LIF & TNFRI \\
\hline
\end{tabular}


Table 2: Gender, race, age, diagnosis and JAK2 V6I7F status of patients whose neutrophils were analyzed for gene and microRNA expression profiling

\begin{tabular}{cccccc}
\hline Patient & Gender & Race & Age (years) & Diagnosis & JAK2 V6I 7F \\
\hline I & Female & Caucasian & 45 & ET & Positive \\
2 & Male & Caucasian & 47 & ET & Negative \\
3 & Female & Caucasian & 63 & PV & Positive \\
4 & Male & Caucasian & 62 & PV & Positive \\
5 & Female & Caucasian & 57 & PV & Negative \\
7 & Male & Caucasian & 52 & PV & Positive \\
\hline
\end{tabular}

ET = essential thrombocytosis

$\mathrm{PV}=$ polycythemia vera

group with 3 healthy subject, 2 MPD, and 1 G-CSF-mobilized neutrophils (Figure 1).

These results showed that the gene expression profile of MPD neutrophils differed from that of healthy subject neutrophils and G-CSF-mobilized neutrophils. Further analysis found that the expression of 1,006 genes differed among neutrophils from the MPD patients, healthy subjects, and healthy subjects given G-CSF (F-test, $\mathrm{p} \leq 0.005$ ). Hierarchical clustering analysis of these 1,006 genes separated the neutrophils into 3 groups; one contained neutrophils from 5 of $6 \mathrm{MPD}$ patients, another included neutrophils from 5 healthy subjects and 1 MPD patient, and the third contained neutrophils from all 6 subjects given G-CSF (Figure 2). In this gene expression profile the MPD neutrophils aligned closer to the healthy subject neutrophils than the G-CSF-mobilized neutrophils. Two clusters of genes distinguished the MPD neutrophils from the healthy subject neutrophils. One cluster was made up of 17 genes whose expression was increased more in MPD neutrophils than in neutrophils from healthy subjects or healthy subjects given G-CSF (Figure 2, cluster 1) and another contained 38 genes down-regulated in MPD neutrophils but not in healthy subjects or G-CSF mobilized neutrophils (Figure 2, cluster 2). The cluster of MPD upregulated genes included FRAT1, ZNF652, LMO4, IL10RB, and cystathionine $\beta$-synthase (CBS). FRAT1 is a regulator of the Wnt signaling pathway and is overexpressed in esophageal squamous cell carcinoma [20]. ZNF652 has a role in the suppression of breast oncogenesis and vulvar cancer $[21,22]$. LMO4 is a transcription regulator and increased expression of $\mathrm{LMO} 4$ in pancreatic ductal adenocarcinoma is associated with a survival advantage [23]. The expression of CBS has been previously reported to be up-regulated in neutrophils from patients with MPDs [24]. Among the down-regulated genes were ribosomal proteins including 3 copies of RPL10, 2 copies of RPL3, and RPS9, RPS10P3, and RPL12P6; proteosome proteins including 3 copies of PSMD2 and PSMC; and cytochrome c oxidases COX5B and COX7A2.
To further explore the differences between MPD and GCSF-mobilized neutrophils, the genes differentially expressed in MPD neutrophils compared to healthy subject neutrophils were identified as well as those differentially expressed in G-CSF-mobilized-neutrophils. MPD neutrophil differentially expressed genes were more likely to belong to inflammatory pathways (Figure 3A). In contrast, G-CSF-mobilized neutrophils differentially expressed genes were more likely to belong to metabolic pathways (Figure 3B).

To further characterize MPD neutrophils, we identified those differentially expressed genes whose expression was increased or decreased to the greatest fold as compared to the healthy subjects. Among the 30 genes whose expression was increased to the greatest extent in MPD neutrophils were ZNF652, CBS, LMO4, AXUD1, MCL1 and CCR1 (Table 3). AXUD1 is a regulator of the Wnt signaling pathway and is down-regulated in lung, kidney, and colon cancer [25]. MCL-1 is a member of the Bcl-2 family and is an important anti-apoptotic molecule for multiple types of hematopoietic cells [26]. CCR1 is a chemokine receptor for at least 11 different chemokines including CCL3 (MIP-1 $\alpha$ ), CCL5 (RANTES), CCL7 (MCP-3), CCL8 (MCP-2), CCL14, CCL15, CCL16 and CCL23 [27]. Among the genes down-regulated most in MPD neutrophils were neutrophil elastase 2 (ELA2) and two NF-k $\beta$ pathway genes (NFKBIA and NFKBIE) all of which are involved in inflammation (Table 4).

We used qRT-PCR to further confirm the differential expression of 3 NFKB pathway genes, NFKBIA, NFKBIE and TNFAIP3 as well as MCL1 and CBS (Figure 4). This confirmed that the expression of NFKBIA, NFKBIE, and TNFAIP3 were significantly down-regulated in both MPD and G-CSF-mobilized neutrophils compared to those from healthy subjects. The expression of CBS was significantly up-regulated in MPD neutrophils and the expression of MCL1 was up-regulated but not to a significant degree as compared to healthy subjects. 



Figure I

Gene expression analysis of MPD neutrophils. Gene expression of neutrophils from 6 MPD patients, 5 healthy subject neutrophils and 6 healthy subjects given G-CSF was analyzed using a microarray with more than 35,000 probes. The 3,617 genes that were expressed in at least $80 \%$ of samples and were up-regulated at least two-fold in one sample were analyzed by unsupervised hierarchical clustering of Eisen. The purple bar indicates neutrophils from patients with MPDs and the yellow bar those from healthy subjects and the blue bar from healthy subjects given G-CSF.

\section{Micro RNA Expression Results}

MicroRNA expression was compared among MPD, GCSF-mobilized and healthy subject neutrophils using a microarray. Among the 827 probes, 500 remained after selecting only those expressed in $>80 \%$ of samples. Unsupervised hierarchical clustering analysis of the neutrophil samples separated the samples into two groups. One group included 3 G-CSF-mobilized neutrophils and 3 healthy subject neutrophils and the second included $3 \mathrm{G}-$ CSF-mobilized neutrophils, 6 MPD neutrophils and 5 normal donor neutrophils (data not shown).

Comparison of the expression of microRNA between MPD and healthy subject neutrophils found that the expression of 21 microRNA were up-regulated in MPD neutrophils and 11 were down-regulated $(\mathrm{p}<0.05)$. Among the microRNA up-regulated in MPD neutrophils were 5 that were increased more than 2-fold; miR-219, miR-515-5p, miR-142-5p, miR-143, and miR-101 (Table 5). The up-regulation of miR-219 in MPD neutrophils compared to those from healthy subjects was confirmed by qRT-PCR (Figure 5). Interestingly, miR-219 has been found to be expressed in the brain and its levels exhibit circadian rhythms and are involved in the control of the suprachiasmatic nuclei (SCN), the master circadian clock in mammals [28]. The expression of 142-5p has also been found to be increased in peripheral blood leukocytes [12]. MicroRNA miR-143 has been found to be involved with cell differentiation. The differentiation of pre-adipocytes to adipocytes is associated with the increased levels of miR-143 [29]. Bruchova and colleagues have found that miR-143 is up-regulated in neutrophils from patients with polycythemia vera [30]. The expression of miR-143 is down-regulated in B cell malignancies, Burkitt's lymphoma cell lines [31], and colorectal cancer [32].

Among the microRNA down-regulated in MPD neutrophils the expression of five were decreased more than 2-fold: miR-133a, miR-504, miR-565, miR-1, and miR216 (Table 5). The down-regulation of miR-133a in MPD neutrophils was confirmed by qRT-PCR (Figure 5 ). MicroRNA miR-133a and - 1 are clustered on the same chromosome and are transcribed together as a single transcript $[33,34]$. These two microRNA are preferentially expressed in brown adipocytes [35], cardiac, and skeletal muscle [34] and are important in the differentiation and regulation of cardiac and skeletal muscle. Little is known about miR-216, -504 and -565. Micro RNA-216 is expressed by the pancreas. A comparison of normal pancreas with 33 other tissues found that the expression of miR-216 and miR-217 and the lack of expression of miR-133a were characteristic of pancreatic tissue [36]. 
1.





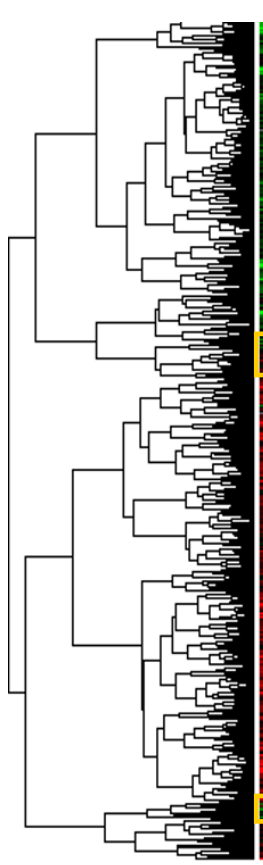

\section{西}

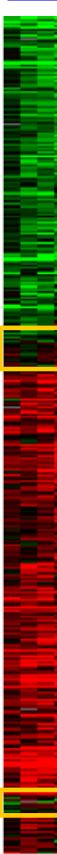



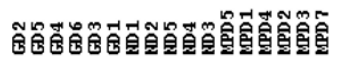

2.

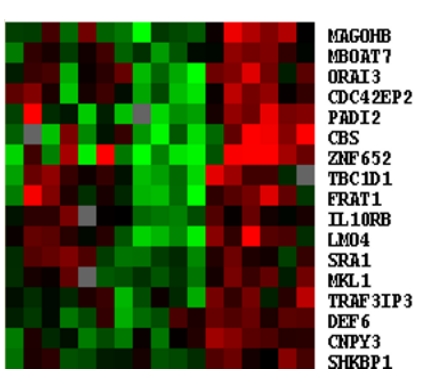

2.

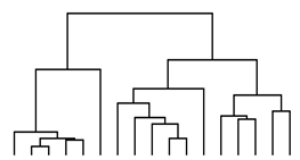

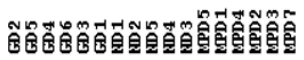

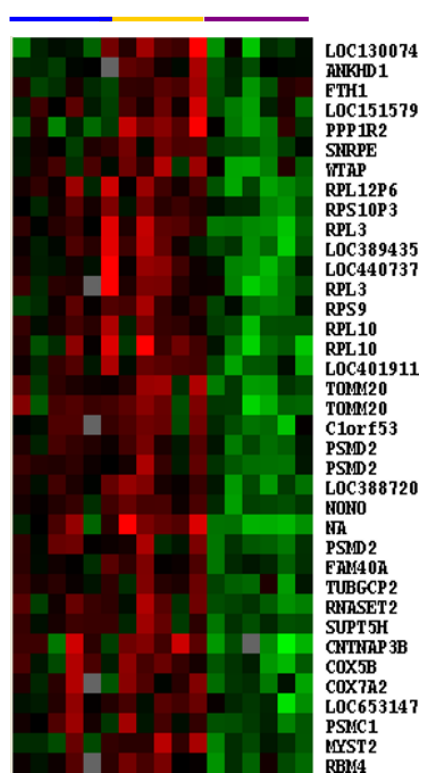

\section{Figure 2}

Gene expression profiling of differentially expressed MPD neutrophil genes. The I,006 genes differentially expressed among 6 MPD patients, 5 healthy subjects and 6 subjects given 5 days of G-CSF (F-test, $P<0.005$ ) were analyzed by hierarchical clustering of Eisen. Genes in cluster I were up-regulated only in MPD neutrophils and those in cluster 2 were down-regulated only in MPD neutrophils. The purple bar indicates neutrophils from patients with MPDs and the yellow bar those from healthy subjects and the blue bar from healthy subjects given G-CSF.

\section{Serum Protein Levels}

The levels of 64 serum proteins were compared in the 6 MPD patients and 7 healthy subjects. The levels of the 64 factors in each of the 6 MPD patients and 7 healthy controls were analyzed by supervised hierarchical clustering analysis (Figure 6). The MPD samples were characterized by 33 proteins whose levels were greater than in healthy subjects. Eleven of these were significantly increased in MPD patients compared to healthy subjects (t-tests, $\mathrm{p}<$ 0.05 , Table 6) and included 2 chemokines (CXCL11 and CCL3), a cytokine (IL-1a), 2 matrix metalloproteinases (MMPs) (MMP-10 and MMP-13), growth factors (PDGFBB and G-CSF) VCAM, TIMP-1, IL-6R and P-selectin.

\section{Expression of Neutrophil Membrane Molecules}

Neutrophil expression of CD11b, CD15, CD16, CD18 and CD177 was analyzed by flow cytometry in 24 patients with MPD (11 PV and $13 \mathrm{ET}$ ). JAK2 V617F was detected in 13 of the 24 patients and one was homozygous (Table 7). Expression was compared to 43 healthy subjects and 27 healthy subjects who were given 5 daily doses of G-CSF.

CD15 and CD18 expression differed among MPD patients and healthy subjects, but not that of CD11b, CD16 or CD177. More neutrophils expressed CD15, Lewis-x, in people with MPD than in healthy subjects (50 $\pm 31 \%$ versus $21 \pm 25 \%, p<0.0002$ ) (Table 7 , Figure 7 ) This was the case for both subjects with PV and ET. The proportion of neutrophils expressing CD18 was also increased in people with MPD $(73 \pm 26 \%$ versus $48 \pm$ $33 \%, \mathrm{p}<0.003)$, although the mean neutrophil fluorescent intensity was reduced $(250 \pm 81$ versus $451 \pm 300, \mathrm{p}$ $<0.003$ ) (Table 7, Figure 7), but was similar to G-CSF stimulated neutrophils. Both the proportion of neu- 
A

B Cell Receptor Signaling
GM-CSF Signaling
IL-10 Signaling
Protein Ubiquitination Pathway
Leukocyte Extravasation Signaling
IL-8 Signaling
NRF2-mediated Oxidative Stress Response
Integrin Signaling
VEGF Signaling
Fcy Receptor-mediated Phagocytosis in MPs
Neurotrophin/TRK Signaling
p53 Signaling
PTEN Signaling
IL-6 Signaling
PI3K/AKT Signaling
Erythropoietin Signaling
Clatrin-mediated Endocytosis
Fc Epsilon RI Signaling
Estrogen Receptor Signaling
Death Receptor Signaling
Regulation of Actin-based Motility by Rho
O-Glycan Biosynthesis
TGF- ${ }^{2}$ Signaling
Actin Cytoskeleton Signaling
Glucocorticoid Receptor Signaling
GABA Receptor Signaling
Chemokine Signaling
14-3-3-mediated Signaling
Hepatic Fibrosis / Hepatic Stellate Cell Activation
Apoptosis Signaling

B

Oxidative Phosphorylation
NRF2-mediated Oxidative Stress Response
Glycosaminoglycan Degradation
IL-10 Signaling
Glycolysis/Gluconeogenesis
Eicosanoid Signaling
Mitochondrial Dysfunction
Ubiquinone Biosynthesis
Fcy Receptor-mediated Phagocytosis in MPs
Pentose Phosphate
Glutathione Metabolism
Chemokine Signaling
Pyruvate Metabolism
Citrate Cycle
Ceramide Signaling
Propanoate Metabolism
Galactose Metabolism
Purine Metabolism
Aryl Hydrocarbon Receptor Signalin
Regulation of Actin-based Motility by Rho
Antigen Presentation Pathway
p53 Signaling
IL-6 Signaling
Estrogen Receptor Signaling
Arachidonic Acid Metabolism
Nicotinate and Nicotinamide Metabolism
Cadrenergic Signaling
EGF Signaling

\section{Figure 3}

Panel A. Pathway analysis of differentially expressed MPD genes. Ingenuity pathway analysis showing canonical pathways significantly modulated by the genes whose expression differed among the MPD neutrophils compared to healthy subject neutrophils $(p<0.05)$. A total of I,270 genes were differentially expressed: 473 were up-regulated and 800 were down-regulated. Only the 30 pathways with the most significant changes are shown. The $p$ value for each pathway is indicated by the bar and is expressed as $-I$ times the log of the $p$ value. The line represents the ratio of the number of genes in a given pathway that meet the cutoff criteria divided by the total number of genes that make up that pathway. Panel B. Pathway analysis of differentially expressed G-CSF genes. Ingenuity pathway analysis showing canonical pathways significantly modulated by the genes whose expression differed among the G-CSF-mobilized neutrophils compared to healthy subject neutrophils $(\mathrm{p}<0.05)$. A total of 909 genes were differentially expressed: 452 were up-regulated and 457 were down-regulated. Only the 30 pathways with the most significant changes are shown. The $p$ value for each pathway is indicated by the bar and is expressed as $-I$ times the $\log$ of the $p$ value. The line represents the ratio of the number of genes in a given pathway that meet the cutoff criteria divided by the total number of genes that make up that pathway.

trophils expressing CD177 and the mean fluorescence intensity of neutrophils were increased slightly in MPD neutrophils, but these changes were not significant.

Following G-CSF administration, the expression of CD16 and CD18 as assessed by the mean fluorescence intensity decreased (Table 7, Figure 7). In contrast, the number of neutrophils expressing CD177 and the mean fluorescence intensity of CD177 expression increased.
The expression of several other neutrophil adhesion molecules, Fc receptors and other antigens were compared in the same cohort of 6 MPD patients in whom gene and $\mathrm{miR}$ expression profiles and serum proteins were measured; 4 with PV and 2 with ET. The proportion of neutrophils expressing CD64 was greater in MPD patients than in healthy subjects $(13 \pm 9 \%$ versus $6 \pm 4 \%, \mathrm{p}<0.05)$ but not the mean fluorescence intensity ( $373 \pm 73$ versus $201 \pm 63)$. There was no difference in the expression of 
Table 3: Genes up-regulated the most in MPD neutrophils compared to those from healthy subjects ( $p<0.05$, tests)

\begin{tabular}{|c|c|c|c|}
\hline Gene & & Fold increase & $\mathbf{p}$ \\
\hline Rg9mtdI & PREDICTED: RNA (guanine-9-) methyltransferase domain containing I (Rg9mtdI) & 4.79 & 0.00844 \\
\hline HPR & haptoglobin-related protein (HPR) & 4.55 & 0.000443 \\
\hline $\mathrm{ZDHHCl} 9$ & zinc finger, DHHC-type containing 19 (ZDHHCI9) & 4.34 & 0.00278 \\
\hline ZNF652 & zinc finger protein 652 (ZNF652) & 3.90 & $5.90 \mathrm{E}-05$ \\
\hline $\mathrm{ADCY} 3$ & adenylate cyclase 3 (ADCY3) & 3.64 & 0.0121 \\
\hline PROK2 & Prokineticin 2 & 3.60 & 0.000166 \\
\hline C19orf59 & chromosome 19 open reading frame 59 (C19orf59) & 3.33 & 0.0139 \\
\hline ZFYVE2I & zinc finger, FYVE domain containing $2 I$ (ZFYVE2I) & 3.32 & 0.00362 \\
\hline CCRI & chemokine (C-C motif) receptor I (CCRI) & 3.14 & 0.000335 \\
\hline EGRI & early growth response I (EGRI) & 3.13 & 0.0229 \\
\hline ST3GAL4 & ST3 beta-galactoside alpha-2,3-sialyltransferase 4 (ST3GAL4) & 3.13 & 0.00225 \\
\hline PADI2 & peptidyl arginine deiminase, type II (PADI2) & 3.12 & $2.90 \mathrm{E}-06$ \\
\hline AXUDI & AXINI up-regulated I (AXUDI) & 3.08 & 0.00546 \\
\hline \multirow[t]{2}{*}{ LOC728488 } & $\begin{array}{l}\text { PREDICTED: similar to Nuclear envelope pore membrane protein POM I2I (Pore membrane protein of I2I kDa) (PI45) } \\
\text { (LOC728488) }\end{array}$ & 3.06 & 0.00241 \\
\hline & Transcribed locus, moderately similar to XP_001235777.I PREDICTED: hypothetical protein [Gallus gallus] & 3.04 & 0.0123 \\
\hline \multirow[t]{2}{*}{ CBS } & cystathionine-beta-synthase (CBS) & 2.97 & 0.00183 \\
\hline & CDNA: FLJ21549 fis, clone COL06253 & 2.96 & 0.00649 \\
\hline ACRVI & acrosomal vesicle protein I (ACRVI), transcript variant II. & 2.91 & 0.00574 \\
\hline UPF2 & UPF2 regulator of nonsense transcripts homolog (yeast) & 2.84 & 0.0179 \\
\hline GYGI & glycogenin I (GYGI) & 2.75 & 0.0146 \\
\hline NTRK2 & neurotrophic tyrosine kinase, receptor, type 2 (NTRK2), transcript variant c & 2.73 & 0.00792 \\
\hline LMO4 & LIM domain only 4 (LMO4) & 2.69 & 0.000128 \\
\hline $\mathrm{MCLI}$ & myeloid cell leukemia sequence I (BCL2-related) (MCLI), transcript variant I & 2.67 & 0.000287 \\
\hline LOC729915 & $\begin{array}{l}\text { PREDICTED: similar to Nuclear envelope pore membrane protein POM I2I (Pore membrane protein of I2I kDa) (PI45) } \\
\text { (LOC7299|5) }\end{array}$ & 2.57 & 0.0172 \\
\hline GALNTI4 & UDP-N-acetyl-alpha-D-galactosamine:polypeptide N-acetylgalactosaminyltransferase I4 (GalNAc-TI4) (GALNTI4) & 2.57 & 0.00853 \\
\hline FAM69A & family with sequence similarity 69 , member A (FAM69A) & 2.57 & 0.0446 \\
\hline MED26 & Mediator complex subunit 26 & 2.56 & 0.0109 \\
\hline ClorflI5 & chromosome I open reading frame II5 (ClorfII5) & 2.55 & 0.0309 \\
\hline KIFC3 & kinesin family member C3 (KIFC3) & 2.54 & 0.00290 \\
\hline Rg9mtdI & Transcribed locus & 2.53 & 0.0113 \\
\hline
\end{tabular}


Table 4: Genes down-regulated the most in MPD neutrophils compared to those from healthy subjects ( $p<0.05$, $t$-tests)

\begin{tabular}{|c|c|c|c|}
\hline Gene & & Fold Increase & $\mathbf{p}$ \\
\hline TPMT & thiopurine S-methyltransferase (TPMT) & 6.90 & $2.14 \times 10^{-4}$ \\
\hline & CDNA FLJ35883 fis, clone TESTI2008929 & 4.47 & 0.00636 \\
\hline ZNF75 & zinc finger protein 75 (D8C6) (ZNF75), mRNA. & 4.29 & $3.24 \times 10^{-3}$ \\
\hline FAM3B & family with sequence similarity 3 , member B (FAM3B), transcript variant 2 & 4.20 & $2.11 \times 10^{-3}$ \\
\hline UBE2D4 & ubiquitin-conjugating enzyme E2D 4 (putative) (UBE2D4) & 4.10 & $3.44 \times 10^{-3}$ \\
\hline $\mathrm{AK} 2 \mathrm{P} 2$ & PREDICTED: adenylate kinase 2 pseudogene 2 (AK2P2) & 3.63 & $8.43 \times 10^{-3}$ \\
\hline XP_933530.1 & PREDICTED: hypothetical protein XP_933530 [Source:RefSeq_peptide_predicted;Acc:XP_933530] & 3.61 & $6.61 \times 10^{-4}$ \\
\hline \multirow[t]{2}{*}{ PVRL2 } & poliovirus receptor-related 2 (herpesvirus entry mediator B) (PVRL2), transcript variant alpha & 3.27 & 0.0418 \\
\hline & CDNA FLJ38039 fis, clone CTONG20I3934 & 3.13 & $9.00 \times 10^{-7}$ \\
\hline NFKBIA & nuclear factor of kappa light polypeptide gene enhancer in B-cells inhibitor, alpha (NFKBIA) & 3.11 & $4.23 \times 10^{-3}$ \\
\hline NFKBIA & nuclear factor of kappa light polypeptide gene enhancer in B-cells inhibitor, alpha (NFKBIA) & 3.07 & $5.02 \times 10^{-3}$ \\
\hline GADD45B & growth arrest and DNA-damage-inducible, beta (GADD45B), mRNA. & 3.06 & 0.0158 \\
\hline PERI & period homolog I (Drosophila) (PERI), mRNA. & 2.92 & $6.84 \times 10^{-3}$ \\
\hline C9orf89 & chromosome 9 open reading frame 89 (C9orf89), mRNA. & 2.91 & $3.51 \times 10^{-4}$ \\
\hline DYNCILII & dynein, cytoplasmic I, light intermediate chain I (DYNCILII) & 2.89 & $2.53 \times 10^{-3}$ \\
\hline RYBP & RINGI and YYI binding protein (RYBP) & 2.88 & $7.27 \times 10^{-3}$ \\
\hline WRB & tryptophan rich basic protein (WRB) & 2.85 & $2.21 \times 10^{-3}$ \\
\hline ELA2 & elastase 2, neutrophil (ELA2) & 2.82 & 0.0180 \\
\hline CNTNAP3B & $\begin{array}{l}\text { OTTHUMP00000046 146|hypothetical protein LOC389722|novel protein similar to contactin associated protein-like } 3 \\
\text { (CNTNAP3) }\end{array}$ & 2.82 & $6.20 \times 10^{-6}$ \\
\hline UBE2E2 & ubiquitin-conjugating enzyme E2E 2 (UBC4/5 homolog, yeast) (UBE2E2) & 2.80 & $8.14 \times 10^{-4}$ \\
\hline ARLIO & ADP-ribosylation factor-like 10 (ARLI0) & 2.79 & $6.80 \times 10^{-3}$ \\
\hline RPS28 & ribosomal protein S28 (RPS28) & 2.76 & $1.28 \times 10^{-4}$ \\
\hline CI5orf29 & chromosome 15 open reading frame 29 ( $\mathrm{Cl} 5$ orf29) & 2.76 & $9.34 \times 10^{-3}$ \\
\hline C20orfl99 & chromosome 20 open reading frame 199 (C20orf199) & 2.71 & $2.28 \times 10^{-5}$ \\
\hline GADD45B & Growth arrest and DNA-damage-inducible, beta & 2.69 & $5.09 \times 10^{-3}$ \\
\hline NFKBIE & nuclear factor of kappa light polypeptide gene enhancer in B-cells inhibitor, epsilon (NFKBIE) & 2.66 & 0.0271 \\
\hline SCARBI & scavenger receptor class $B$, member I (SCARBI), transcript variant I & 2.63 & 0.0485 \\
\hline TSP50 & testes-specific protease 50 (TSP50) & 2.62 & $8.76 \times 10^{-3}$ \\
\hline EFR3B & PREDICTED: EFR3 homolog B (S. cerevisiae) (EFR3B) & 2.60 & 0.021 \\
\hline MLSTDI & male sterility domain containing I (MLSTDI) & 2.59 & 0.0134 \\
\hline
\end{tabular}


CD10, CD31, CD44, CD45, CD55, CD59, and CD62L among neutrophils from MPD patients and healthy subjects (data not shown).

\section{Discussion}

In order to better characterize the molecular basis of MPDs, we compared gene and miRNA expression profiles of neutrophils from MPD patients with those from healthy subjects. We identified several genes and microRNA whose expression differed in MPD neutrophils compared to those of healthy subjects. Since most patients with PV and approximately half with ET have a gain-offunction mutation in JAK2, we also compared MPD neutrophils with neutrophils from healthy subjects treated with G-CSF, a hematopoietic growth factor that signals through JAK2. While there were similarities in gene expression signatures in MPD neutrophils and G-CSF- mobilized neutrophils, we also found several differences. The expression of a greater number of genes was changed in G-CSF-mobilized neutrophils compared to MPD neutrophils. There were also a number of genes whose expression changed in MPD neutrophils, but not in G-CSFmobilized neutrophils. In addition, several microRNAs were differentially expressed by MPD neutrophils. Many of these gene and microRNA expression changes were similar to those found in hypertrophied cells, cancers, and hematologic malignancies.

Among the microRNA that were down-regulated in MPD neutrophils were two closely associated down-regulated microRNA; miR-133a and miR-1. These two miR are located in the same bicistronic unit on chromosome 18, are transcribed together [34], and are involved in skeletal muscle and myocardial muscle differentiation and prolif-
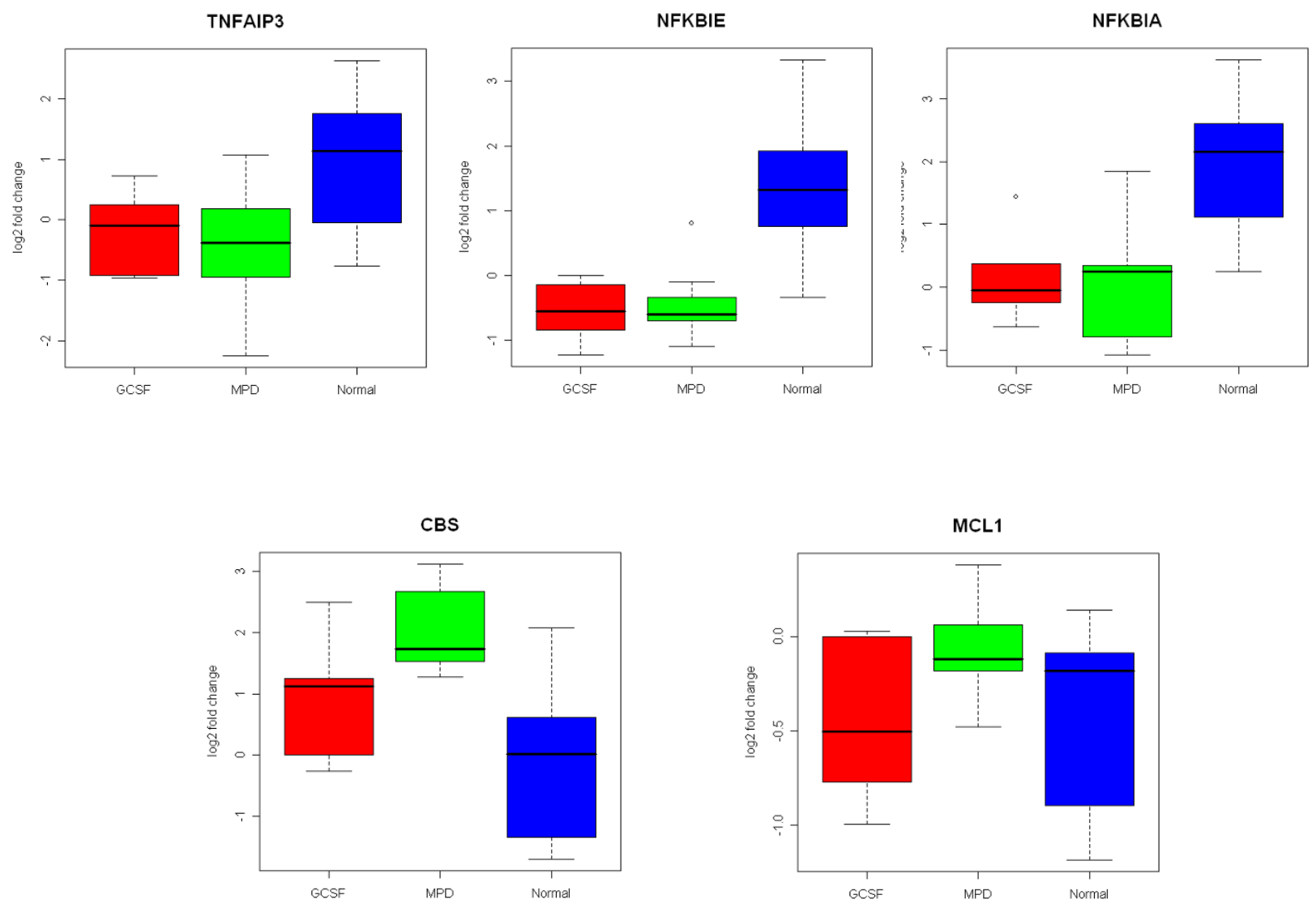

\section{Figure 4}

Analysis of differentially expressed MPD neutrophil genes by quantitative real time PCR (RT-PCR). The expression of five genes NFKBIA, NFKBIE, TNFAIP3, MCLI and CBS in MPD neutrophils was analyzed by qRT-PCR. The expression of NFKBIA, NFKBIE, and TNFAIP3 were down-regulated in MPD and G-CSF-mobilized neutrophils. The expression of CBS was significantly increased in MPD neutrophils. The expression of MCLI was also increased in MPD neutrophils but the difference was not significant. The results of analysis by $\mathrm{qRT}-\mathrm{PCR}$ and gene expression profiling were similar. 
Table 5: MPD neutrophil differentially expressed microRNA (miR)*

\begin{tabular}{cccc}
\hline \multicolumn{2}{c}{ Up-regulated miR } & \multicolumn{2}{c}{ Down-regulated miR } \\
\hline Description & Fold change & Description & Fold change \\
\hline hsa-miR-219 & 4.1I & hsa-miR-133a & 3.41 \\
hsa-miR-515-5p & 2.63 & hsa-miR-504 & 2.73 \\
hsa-miR-142-5p & 2.47 & hsa-mir-565 & 2.52 \\
hsa-miR-143 & 2.43 & hsa-miR-I & 2.16 \\
hsa-miR-10I & 2.21 & hsa-miR-216 & 2.14 \\
hsa-miR-424 & 1.93 & hsa-miR-485-5p & 1.76 \\
hsa-miR-450 & 1.92 & hsa-miR-483 & 1.71 \\
hsa-miR-30I & 1.86 & hsa-mir-657 & 1.62 \\
hsa-miR-33 & 1.86 & hsa-miR-502 & 1.59 \\
hsa-miR-19b & 1.81 & hsa-mir-6I5 & 1.43 \\
hsa-miR-29b & 1.76 & hsa-mir-42I & 1.32 \\
hsa-miR-30a-5p & 1.73 & & \\
hsa-miR-29c & 1.70 & & \\
hsa-miR-185 & 1.66 & & \\
hsa-miR-2I & 1.63 & & \\
hsa-miR-19a & 1.6 & & \\
hsa-miR-200b & 1.48 & & \\
hsa-miR-542-3p & 1.43 & & \\
hsa-mir-625 & 1.42 & \\
hsa-miR-106b & 1.33 & & \\
hsa-miR-20b & 1.31 & & \\
& & & \\
& & \\
\end{tabular}

$* \mathrm{p}<0.05$ compared to healthy subject neutrophils

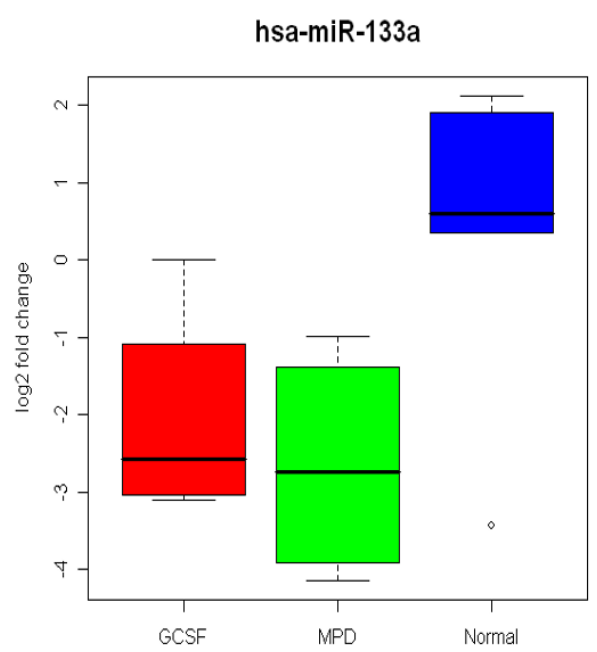

eration. The down-regulation of miR-133a and miR-1 is associated with hypertrophic myocardium and skeletal muscle [33,37-39]. The suppression of miR-133 has been shown to induce cardiac hypertrophy [37]. miR-133a down-regulation has been noted in squamous cell carcinoma of the tongue $[40,41]$. In addition, the expression of miR-1 is also reduced in heptocellular carcinoma [42] and lung cancer [43]. Down-regulation of these two microRNAs may play a role in the proliferation of hematopoietic cells in MPDs.

Gene expression analysis found that MPD neutrophils exhibited a pro-inflammation profile. MPD differentially expressed genes included those involved with B cell, IL-6, IL- 8 , VEGF, TGF- $\beta$, Fc $\varepsilon$ RI and integrin signaling pathways. These changes are not simply due to the constitutive activation of JAK2 since they were not present in G-CSFmobilized neutrophils. Instead, most G-CSF-mobilized neutrophils differentially expressed genes were in metabolic and synthesis pathways.

Analysis of specific genes whose expression changed in MPD neutrophils identified several genes in the NF- $\kappa B$ pathway. Change in expression of 3 of these genes was confirmed by qRT-PCR. The expression of several NF- $\kappa B$ genes were increased and several were decreased so the overall effect on the pathway is not certain, however, the

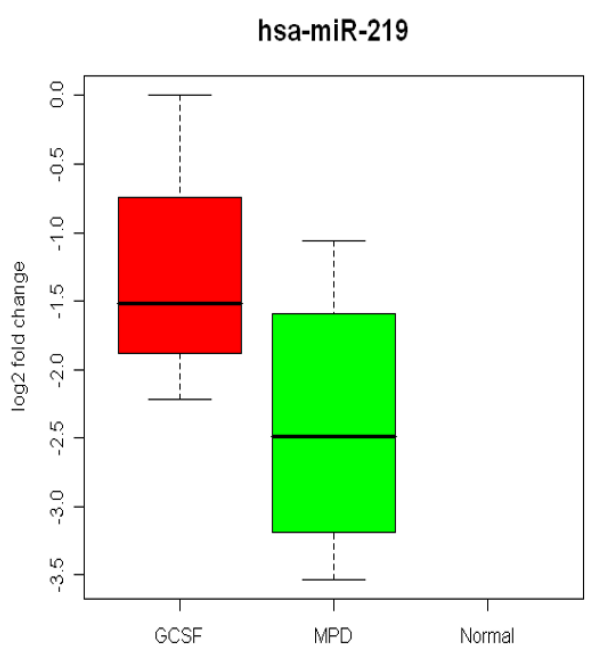

\section{Figure 5}

Analysis of differentially expressed MPD neutrophil microRNA by quantitative real time PCR (qRT-PCR). The expression of miR-133a and miR-219 were analyzed by qRT-PCR. The expression of miR-133a was down-regulated in both MPD and G-CSF-mobilized neutrophils while that of miR-219 was up-regulated in MPD and G-CSF-mobilized neutrophils. In fact, no miR-2 19 transcripts were detected in neutrophils from healthy subjects. The results of analysis by qRT-PCR and microRNA expression profiling were similar. 
Table 6: Serum factors whose levels differed between MPD patients and healthy subjects.

\begin{tabular}{|c|c|c|c|}
\hline Factor & Healthy Subjects $(n=7)$ & $\begin{array}{l}\text { MPD Patients } \\
(n=6)\end{array}$ & $\mathbf{P}$ \\
\hline VCAM & $\mathrm{I}, 707,2 \mathrm{I} \mathrm{I} \pm 5,080$ & $10,467,524 \pm 7,793,493$ & 0.0123 \\
\hline MMP-IO & $716 \pm 195$ & $\mathrm{I}, 672 \pm 854$ & 0.0145 \\
\hline MIP-I $\alpha(C C L 3)$ & $62.6 \pm 9.9$ & $93.5 \pm 27.8$ & 0.0185 \\
\hline MMP-I3 & $54.1 \pm 63.1$ & $1,181 \pm 1091$ & 0.0190 \\
\hline IL-6R & $5,215 \pm 1,606$ & $8,421 \pm 2,684$ & 0.0220 \\
\hline TIMP-I & $287,485 \pm 89,954$ & $930,916 \pm 650,021$ & 0.0209 \\
\hline$P$ selectin & $131,558 \pm 35,298$ & $527,593 \pm 45,1417$ & 0.0249 \\
\hline ITAC (CXCLII) & $21.0 \pm 13.0$ & $338 \pm 330$ & 0.0263 \\
\hline G-CSF & $61.1 \pm 7.5$ & $109.0 \pm 52.9$ & 0.0352 \\
\hline PDGFBB & $473.1 \pm 239$ & $1,962 \pm 1,665$ & 0.0381 \\
\hline IL-I $\alpha$ & $\mathrm{II} . \mathrm{I} \pm 6.5$ & $39.4 \pm 32.1$ & 0.0421 \\
\hline
\end{tabular}

Values are expressed as mean $\pm \mathrm{SD}$ in $\mathrm{pg} / \mathrm{ml}$

NF- $\kappa B$ pathway is likely important in MPD. NF- $\kappa \mathrm{B}$ promotes the survival, proliferation, differentiation and survival of lymphocytes and plasma cells $[44,45]$. NF- $\kappa$ B is also activated in chronic myeloid leukemia (CML) [46], but it has not been reported to be activated in MPDs [44]. In CML increased levels of NF- $\kappa \mathrm{B}$ may be a down stream effect of brc-abl activation [46]. In our studies we also found that the expression of many NF- $\mathrm{kB}$ pathway genes were changed in neutrophils by G-CSF and it may be that constitutive activation of JAK2 in MPD results in NF-KB activation in PV and ET neutrophils.

The expression of CCR1 was increased in MPD patients. CCR1 is an important leukocyte chemokine receptor for several ligands including CCL3 or MIP-1 $\alpha$. The levels of 11 serum factors were elevated in ET and PV patients including CCL3 which can be a chemoattractant to activated neutrophils. These results suggest that the increased expression of CCR1 and CCL3 may contribute to the proinflammatory profile of MPD neutrophils.

Changes in serum protein levels and neutrophil antigen expression in PV and ET patients do not appear to be simply a result of constitutive activation of neutrophil JAK2. G-CSF signals through JAK2, but changes in these markers are different in healthy subjects given G-CSF than those in MPD patients. The levels of several factors are elevated in subjects given G-CSF that were not elevated in MPD patients including E-selectin, L-selectin, MMP-1, MMP-8, IL-2R，IL-10，IL-2R, TNFR1, hepatocyte growth factor (HGF) and SAA [16]. In addition several serum factors were changed in MPD patients that were not changed in healthy subjects given G-CSF including CXCL11, CCL3, PDGFBB, IL-1a, TIMP1, and P-selectin [16]. Changes in the levels of these serum proteins may be due to shedding

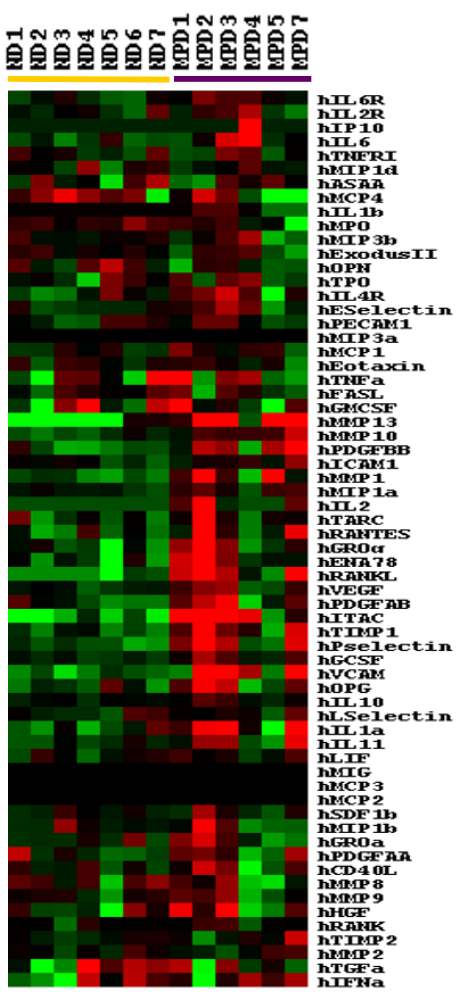

\section{Figure 6}

Comparison of serum protein levels among MPD patients and healthy subjects. Levels of each of the 64 factors were measured by nested ELISA in 6 MPD patients and 7 healthy subjects and the levels were analyzed by supervised hierarchical clustering of Eisen. Higher factor levels were indicated in red and lower levels in green. Samples from MPD patients are shown by the purple bar and from healthy subjects by the yellow bar. 
Table 7: Comparison of neutrophil expression of CDIIb, CD I5, CDI6, CD I8, and CDI77 among MPD patients, healthy subjects, and healthy subjects given G-CSF

\begin{tabular}{|c|c|c|c|c|c|}
\hline & $\begin{array}{l}\text { Healthy Subjects } \\
\quad(n=43)\end{array}$ & $\begin{array}{l}\text { All MPD Patients } \\
(n=24)\end{array}$ & $\begin{array}{l}\text { Polycythemia Vera } \\
(n=I I)\end{array}$ & $\begin{array}{l}\text { Essential Thrombocytosis } \\
\qquad(n=13)\end{array}$ & $\begin{array}{l}\text { G-CSF-Treated Subjects } \\
(\mathrm{n}=27)\end{array}$ \\
\hline \multicolumn{6}{|c|}{$\%$ Reactive cells } \\
\hline CDIIb & $55 \pm 26$ & $54 \pm 28$ & $66 \pm 27$ & $44 \pm 26 \dagger$ & $64 \pm 24$ \\
\hline CDI5 & $21 \pm 25$ & $50 \pm 31 * \dagger$ & $51 \pm 31 * \dagger$ & $49 \pm 33^{*}+$ & $23 \pm 29$ \\
\hline CDI6 & $81 \pm 22$ & $82 \pm 19$ & $83 \pm 24$ & $82 \pm 16$ & $89 \pm 5$ \\
\hline CDI8 & $48 \pm 33$ & $73 \pm 26^{*}$ & $73 \pm 30^{*}$ & $73 \pm 23^{*}$ & $62 \pm 35$ \\
\hline CDI77 & $53 \pm 23$ & $59 \pm 28 \dagger$ & $59 \pm 29 \dagger$ & $58 \pm 27 \dagger$ & $82 \pm 26^{*}$ \\
\hline \multicolumn{6}{|c|}{ Mean Fluorescence Intensity } \\
\hline CDIIb & $|82 \pm 5|$ & $187 \pm 107$ & $|7| \pm 100$ & $200 \pm 115$ & $155 \pm 67$ \\
\hline CDI5 & $480 \pm 284$ & $374 \pm 236$ & $373 \pm 265$ & $377 \pm 221$ & $44 I \pm 443$ \\
\hline CDI6 & $2,946 \pm 1,345$ & $2,580 \pm 1,138 \dagger$ & $2,410 \pm 1,430 \dagger$ & $2,725 \pm 853 \dagger$ & $890 \pm 336 *$ \\
\hline CDI8 & $451 \pm 300$ & $250 \pm 8 I^{*}$ & $267 \pm 100$ & $237 \pm 61^{*}$ & $253 \pm 107^{*}$ \\
\hline CDI77 & $625 \pm 383$ & $575 \pm 267 \dagger$ & $587 \pm 251 \dagger$ & $566 \pm 290 \dagger$ & $2,012 \pm 1088^{*}$ \\
\hline
\end{tabular}

\footnotetext{
$* p<0.05$ compared to healthy subjects

† $\mathrm{p}<0.05$ compared to subjects given G-CSF

Fluor $=$ fluorescence
}

or internal cellular sequestration of their receptors in hematopoietic cells, an inability of the receptor to bind the factor normally, or to increased protein production.

The elevation of many of these proteins could contribute to the clinical manifestations of ET and PV. Changes in serum and plasma protein levels have been studied in patients with PMF which is characterized by bone marrow myelofibrosis, extramedullary hematopoiesis and the presence of immature myeloid cells in the peripheral blood [47]. The release of proteolytic enzymes by PMF mononuclear cells is thought to contribute to the abnormal trafficking of CD34+ cells in PMF patients by degrading HPC adhesion molecules expressed on bone marrow stromal cells and thereby releasing hematopoietic progenitor cells (HPCs) into the circulation. The levels of soluble proteases MMP-9 and neutrophil elastase and VCAM-1 are increased in PMF patients [48]. MMP-9 and elastase are thought to cleave VCAM-1 expressed by stromal cells which leads to the disruption of the interaction of VCAM1 and very late antigen -4 (VLA-4) expressed by HPCs resuling in the release of HPCs. The levels of peripheral blood CD34+ cells are also increased in PV patients and proteases likely contribute to the mobilization of HPCs in PV patients. We found that VCAM-1 levels were also increased in MPD patients as well as the levels of the proteolytic enzymes MMP-13 and MMP-10. The levels of MMP-9 and MMP-2 were also greater in MPD patients, but the difference was not significant.

Other factors may also contribute to the increased levels of circulating HPCs in MPD patients. G-CSF is an impor- tant mobilizer of HPCs and CD34+ cells. We found that G-CSF levels were increased in MPD patients. The levels of CCL3, a chemokine that can mobilize HPCs, were also increased in the MPD patients. Elevated levels of both GCSF and CCL3 may contribute to HPC mobilization in MPD patients.

We also compared the expression of neutrophil surface proteins in ET and PV patients and healthy subjects, but found few differences. Neutrophil expression of CD18 and CD15 was up-regulated in MPD patients. Others have found that the expression of CD18 and CD11b was upregulated on MPD neutrophils $[49,50]$. CD15 functions as a neutrophil adhesion molecule [51] and it is expressed by some types of leukemic cells [52] and by Reed-Sternberg cells [53] but its expression has not been previously analyzed on MPD neutrophils. We confirmed using a larger sample size the findings of Klippel and colleagues that the expression of CD177 is not increased although CD177 mRNA levels are markedly elevated in MPD neutrophils [54].

Comparison of MPD and G-CSF-mobilized neutrophil gene and antigen expression suggests that the changes in MPD neutrophils differ from those induced by G-CSF. These differences may be due to MPD-associated changes in other cell types. While G-CSF primarily affects neutrophils and neutrophil precursors, JAK2 V617F is found in neutrophils, neutrophil precursors, megakaryoctyes and red cell precursors. It may be that the constitutive activation of JAK2 in megakaryocytes and/or red cell precur- 




Figure 7

Comparison of the expression of CD I 5, CD I 8, and CDI 77 by neutrophils from MPD patients, healthy subjects, and healthy subjects given G-CSF. Neutrophil expression of CDI5, CDI8, and CDI77 was analyzed by flow cytometry in 24 MPD patients and 43 healthy subjects. The results are expressed as a percent of neutrophils that were reactive with each antibody. The expression of CDI5 and CDI8 was significantly greater in MPD neutrophils compared to those from healthy subjects, but there was no difference in the expression of CDI 5 and CDI 8 between neutrophils from healthy subjects given GCSF and those who were not. The expression of CDI77 was increased in G-CSF-mobilized neutrophils compared to unmobilized healthy subject and MPD neutrophils, but there was no difference in CDI77 expression between MPD and unmobilized healthy subject neutrophils.

sors results in the secretion of factors by these cells that affects neutrophils.

JAK2 V617F is an important biomarker for MPD, but it would be useful to identify additional new MPD biomarkers. While the levels of 11 serum factors were elevated in ET and PV patients including VCAM-1, MMP-13, CXCL11, IL-1a, TIMP-1, PDGF-BB and P-selectin whose levels were more than 3 -fold greater than the levels in healthy subjects, it is not likely that any of these factors can be used alone as a biomarker for MPD since none was elevated in all MPD patients. The measurement of a combination of factors might serve as a useful biomarker for PV or ET, however, most of the elevated factors are important inflammatory factors and they are likely to be elevated in other disorders. Larger studies are needed which compare the levels of these factors among patients with PV and ET, healthy subjects, and subjects with other hematologic and inflammatory diseases to determine if unique combinations of changes in soluble factor levels are characteristic of these disorders.

\section{Conclusion}

This study provides new sights into the molecular changes in ET and PV. PV and ET neutrophils were characterized by the down-regulation of miR-1 and miR-133a and changes in the expression of many genes involved in inflammation including those in the NF- $\kappa \mathrm{B}$ pathway.

\section{Competing interests}

The authors declare that they have no competing interests.

\section{Authors' contributions}

SS designed the study, performed research, analyzed data and wrote the paper; PJ designed the study, performed research, analyzed data and wrote the paper; LC designed 
the study, preformed research, analyzed data and wrote the paper; JR designed the study, preformed research, and analyzed data; $\mathrm{MB}$ designed the study, analyzed the data and wrote the paper; NZ preformed research and analyzed the data; SA preformed research and analyzed the data; EW designed the study and wrote the paper; JA designed the study and wrote the paper; GS designed the research and wrote the paper; and DS designed the study, analyzed data and wrote the paper.

\section{Acknowledgements}

This study was funded by the Department of Transfusion Medicine, Clinical Center, National Institutes of Health, Bethesda, Maryland, USA

\section{References}

I. Levine RL, Pardanani A, Tefferi A, Gilliland DG: Role of JAK2 in the pathogenesis and therapy of myeloproliferative disorders. Nat Rev Cancer 2007, 7:673-683.

2. James C, Ugo V, Le Couedic JP, Staerk J, Delhommeau F, Lacout C, Garcon L, Raslova H, Berger R, Bennaceur-Griscelli A, Villeval JL, Constantinescu SN, Casadevall N, Vainchenker W: A unique clonal JAK2 mutation leading to constitutive signalling causes polycythaemia vera. Nature 2005, 434: I |44-I | 48

3. Levine RL, Wadleigh M, Cools J, Ebert BL, Wernig G, Huntly BJ, Boggon TJ, Wlodarska I, Clark J], Moore S, Adelsperger J, Koo S, Lee JC, Gabriel S, Mercher T, D'Andrea A, Frohling S, Dohner K, Marynen P, Vandenberghe P, Mesa RA, Tefferi A, Griffin JD, Eck MJ, Sellers WR, Meyerson M, Golub TR, Lee SJ, Gilliland DG: Activating mutation in the tyrosine kinase JAK2 in polycythemia vera, essential thrombocythemia, and myeloid metaplasia with myelofibrosis. Cancer Cell 2005, 7:387-397.

4. Baxter EJ, Scott LM, Campbell PJ, East C, Fourouclas N, Swanton S, Vassiliou GS, Bench AJ, Boyd EM, Curtin N, Scott MA, Erber WN, Green AR: Acquired mutation of the tyrosine kinase JAK2 in human myeloproliferative disorders. Lancet 2005, 365: 1054- $106 \mid$.

5. Kralovics R, Passamonti F, Buser AS, Teo SS, Tiedt R, Passweg JR, Tichelli A, Cazzola M, Skoda RC: A gain-of-function mutation of JAK2 in myeloproliferative disorders. N Engl ] Med 2005, 352: $1779-1790$.

6. Cario H, Goerttler PS, Steimle C, Levine RL, Pahl HL: The JAK2V6I7F mutation is acquired secondary to the predisposing alteration in familial polycythaemia vera. $\mathrm{Br} J$ Haematol 2005, i 30:800-80|.

7. Bellanne-Chantelot C, Chaumarel I, Labopin M, Bellanger F, Barbu V, De Toma C, Delhommeau F, Casadevall N, Vainchenker W, Thomas G, Najman A: Genetic and clinical implications of the Val6 I7Phe JAK2 mutation in 72 families with myeloproliferative disorders. Blood 2006, 108:346-352.

8. Landgren O, Goldin LR, Kristinsson SY, Helgadottir EA, Samuelsson J, Bjorkholm M: Increased risks of polycythemia vera, essential thrombocythemia, and myelofibrosis among 24,577 firstdegree relatives of II,039 patients with myeloproliferative neoplasms in Sweden. Blood 2008, I I 2:2199-2204.

9. Levine RL, Gilliland DG: Myeloproliferative disorders. Blood 2008, II 2:2190-2/98.

10. Tefferi A, Thiele J, Orazi A, Kvasnicka HM, Barbui T, Hanson CA, Barosi G, Verstovsek S, Birgegard G, Mesa R, Reilly JT, Gisslinger H, Vannucchi AM, Cervantes F, Finazzi G, Hoffman R, Gilliland DG, Bloomfield CD, Vardiman JW: Proposals and rationale for revision of the World Health Organization diagnostic criteria for polycythemia vera, essential thrombocythemia, and primary myelofibrosis: recommendations from an ad hoc international expert panel. Blood 2007, I 1 0:1092-1097.

II. Wang E, Miller LD, Ohnmacht GA, Liu ET, Marincola FM: High-fidelity mRNA amplification for gene profiling. Nat Biotechnol 2000, I 8:457-459.

12. Jin P, Wang E, Ren J, Childs R, Shin JW, Khuu H, Marincola FM, Stroncek DF: Differentiation of two types of mobilized peripheral blood stem cells by microRNA and cDNA expression analysis. J Transl Med 2008, 6:39.
13. Eisen MB, Spellman PT, Brown PO, Botstein D: Cluster analysis and display of genome-wide expression patterns. Proc Natl Acad Sci USA 1998, 95: I 4863-I 4868.

14. Dennis G Jr, Sherman BT, Hosack DA, Yang J, Gao W, Lane HC, Lempicki RA: DAVID: Database for Annotation, Visualization, and Integrated Discovery. Genome Biol. 2003, 4(5):P3.

15. Chen C, Ridzon DA, Broomer AJ, Zhou Z, Lee DH, Nguyen JT, Barbisin M, Xu NL, Mahuvakar VR, Andersen MR, Lao KQ, Livak KJ, Guegler KJ: Real-time quantification of microRNAs by stem-loop RT-PCR. Nucleic Acids Res 2005, 33:e I 79.

16. Stroncek D, Slezak S, Khuu H, Basil C, Tisdale J, Leitman SF, Marincola FM, Panelli MC: Proteomic signature of myeloproliferation and neutrophilia: analysis of serum and plasma from healthy subjects given granulocyte colony-stimulating factor. Exp Hematol 2005, 33:1109-11117.

17. Ross DT, Scherf U, Eisen MB, Perou CM, Rees C, Spellman P, lyer V, Jeffrey SS, Van de RM, Waltham M, Pergamenschikov A, Lee JC, Lashkari D, Shalon D, Myers TG, Weinstein JN, Botstein D, Brown PO: Systematic variation in gene expression patterns in human cancer cell lines. Nat Genet 2000, 24:227-235.

18. Wang E, Miller LD, Ohnmacht GA, Mocellin S, Perez-Diez A, Petersen D, Zhao Y, Simon R, Powell JI, Asaki E, Alexander HR, Duray PH, Herlyn M, Restifo NP, Liu ET, Rosenberg SA, Marincola FM: Prospective molecular profiling of melanoma metastases suggests classifiers of immune responsiveness. Cancer Res 2002, 62:358I-3586.

19. Basil CF, Zhao Y, Zavaglia K, Jin P, Panelli MC, Voiculescu S, Mandruzzato S, Lee HM, Seliger B, Freedman RS, Taylor PR, Hu N, Zanovello P, Marincola FM, Wang E: Common cancer biomarkers. Cancer Res 2006, 66:2953-296l.

20. Wang Y, Liu S, Zhu H, Zhang W, Zhang G, Zhou X, Zhou C, Quan L, Bai J, Xue L, Lu N, Xu N: FRATI overexpression leads to aberrant activation of beta-catenin/TCF pathway in esophageal squamous cell carcinoma. Int / Cancer 2008, I 23:56I-568.

21. Kumar R, Manning J, Spendlove HE, Kremmidiotis G, McKirdy R, Lee J, Millband DN, Cheney KM, Stampfer MR, Dwivedi PP, Morris HA, Callen DF: ZNF652, a novel zinc finger protein, interacts with the putative breast tumor suppressor CBFA2T3 to repress transcription. Mol Cancer Res 2006, 4:655-665.

22. Holm R, Knopp S, Kumar R, Lee J, Nesland JM, Trope C, Callen DF: Expression of ZNF652, a novel zinc finger protein, in vulvar carcinomas and its relation to prognosis. J Clin Pathol 2008, 6I:59-63.

23. Murphy NC, Scarlett CJ, Kench JG, Sum EY, Segara D, Colvin EK, Susanto J, Cosman PH, Lee CS, Musgrove EA, Sutherland RL, Lindeman GJ, Henshall SM, Visvader JE, Biankin AV: Expression of LMO4 and outcome in pancreatic ductal adenocarcinoma. Br J Cancer 2008, 98:537-54I.

24. Goerttler PS, Kreutz C, Donauer J, Faller D, Maiwald T, Marz E, Rumberger B, Sparna T, Schmitt-Graff A, Wilpert J, Timmer J, Walz G, Pahl HL: Gene expression profiling in polycythaemia vera: overexpression of transcription factor NF-E2. Br J Haematol 2005, I 29:138-150.

25. Ishiguro $H$, Tsunoda $T$, Tanaka $T$, Fujii $Y$, Nakamura $Y$, Furukawa $Y$ : Identification of AXUDI, a novel human gene induced by AXINI and its reduced expression in human carcinomas of the lung, liver, colon and kidney. Oncogene 200I, 20:5062-5066.

26. Opferman JT: Life and death during hematopoietic differentiation. Curr Opin Immunol 2007, 19:497-502.

27. Cheng JF, Jack R: CCRI antagonists. Mol Divers 2008, I 2:17-23.

28. Cheng HY, Papp JW, Varlamova O, Dziema H, Russell B, Curfman JP, Nakazawa T, Shimizu K, Okamura H, Impey S, Obrietan K: microRNA modulation of circadian-clock period and entrainment. Neuron 2007, 54:813-829.

29. Esau C, Kang X, Peralta E, Hanson E, Marcusson EG, Ravichandran LV, Sun Y, Koo S, Perera RJ, Jain R, Dean NM, Freier SM, Bennett CF, Lollo B, Griffey R: MicroRNA-I 43 regulates adipocyte differentiation. J Biol Chem 2004, 279:5236I-52365.

30. Bruchova $H$, Merkerova M, Prchal JT: Aberrant expression of microRNA in polycythemia vera. Haematologica 2008, 93:1009-1016.

31. Akao Y, Nakagawa Y, Kitade Y, Kinoshita T, Naoe T: Downregulation of microRNAs- I 43 and - 145 in B-cell malignancies. Cancer Sci 2007, 98: $1914-1920$.

32. Slaby O, Svoboda M, Fabian P, Smerdova T, Knoflickova D, Bednarikova M, Nenutil R, Vyzula R: Altered expression of miR-2I, miR- 
3I, miR-I43 and miR-I 45 is related to clinicopathologic features of colorectal cancer. Oncology 2007, 72:397-402.

33. Chen JF, Mandel EM, Thomson JM, Wu Q, Callis TE, Hammond SM, Conlon FL, Wang DZ: The role of microRNA-I and microRNA133 in skeletal muscle proliferation and differentiation. Nat Genet 2006, 38:228-233.

34. Sempere LF, Freemantle S, Pitha-Rowe I, Moss E, Dmitrovsky E, Ambros V: Expression profiling of mammalian microRNAs uncovers a subset of brain-expressed microRNAs with possible roles in murine and human neuronal differentiation. Genome Biol 2004, 5:R I3.

35. Walden TB, Timmons JA, Keller P, Nedergaard J, Cannon B: Distinct expression of muscle-specific microRNAs (myomirs) in brown adipocytes. J Cell Physiol 2009, 2 1 8:444-449.

36. Szafranska AE, Davison TS, John J, Cannon T, Sipos B, Maghnouj A, Labourier E, Hahn SA: MicroRNA expression alterations are linked to tumorigenesis and non-neoplastic processes in pancreatic ductal adenocarcinoma. Oncogene 2007, 26:4442-4452.

37. Care A, Catalucci D, Felicetti F, Bonci D, Addario A, Gallo P, Bang ML, Segnalini P, Gu Y, Dalton ND, Elia L, Latronico MV, Hoydal M, Autore C, Russo MA, Dorn GW, Ellingsen O, Ruiz-Lozano P, Peterson KL, Croce CM, Peschle C, Condorelli G: MicroRNA-133 controls cardiac hypertrophy. Nat Med 2007, 13:6/3-618.

38. Luo X, Lin H, Pan Z, Xiao J, Zhang Y, Lu Y, Yang B, Wang Z: Downregulation of $\mathrm{miR}-\mathrm{I} / \mathrm{miR}-\mathrm{I} 33$ contributes to re-expression of pacemaker channel genes HCN2 and HCN4 in hypertrophic heart. J Biol Chem 2008, 283:20045-20052.

39. McCarthy J], Esser KA: MicroRNA-I and microRNA-133a expression are decreased during skeletal muscle hypertrophy. J Appl Physiol 2007, 102:306-313.

40. Wong TS, Liu XB, Wong BY, Ng RW, Yuen AP, Wei Wl: Mature miR-184 as Potential Oncogenic microRNA of Squamous Cell Carcinoma of Tongue. Clin Cancer Res 2008, 14:2588-2592.

4I. Wong TS, Liu XB, Chung-Wai HA, Po-Wing YA, Wai-Man NR, Ignace WW: Identification of pyruvate kinase type $M 2$ as potential oncoprotein in squamous cell carcinoma of tongue through microRNA profiling. Int / Cancer 2008, I 23:25 I-257.

42. Datta J, Kutay H, Nasser MW, Nuovo GJ, Wang B, Majumder S, Liu CG, Volinia S, Croce CM, Schmittgen TD, Ghoshal K, Jacob ST: Methylation mediated silencing of MicroRNA-I gene and its role in hepatocellular carcinogenesis. Cancer Res 2008, 68:5049-5058

43. Nasser MW, Datta J, Nuovo G, Kutay H, Motiwala T, Majumder S, Wang B, Suster S, Jacob ST, Ghoshal K: Down-regulation of micro-RNA-I (miR-I) in lung cancer. Suppression of tumorigenic property of lung cancer cells and their sensitization to doxorubicin-induced apoptosis by miR-I. J Biol Chem 2008, 283:33394-33405

44. Okamoto T, Sanda T, Asamitsu K: NF-kappa B signaling and carcinogenesis. Curr Pharm Des 2007, I3:447-462.

45. Naugler WE, Karin M: NF-kappaB and cancer-identifying targets and mechanisms. Curr Opin Genet Dev 2008, 18:19-26.

46. Cilloni D, Martinelli G, Messa F, Baccarani M, Saglio G: Nuclear factor $\mathrm{kB}$ as a target for new drug development in myeloid malignancies. Haematologica 2007, 92: I224-1229.

47. Barosi G, Viarengo G, Pecci A, Rosti V, Piaggio G, Marchetti M, Frassoni F: Diagnostic and clinical relevance of the number of circulating CD34(+) cells in myelofibrosis with myeloid metaplasia. Blood 200I, 98:3249-3255.

48. Xu M, Bruno E, Chao J, Huang S, Finazzi G, Fruchtman SM, Popat U, Prchal JT, Barosi G, Hoffman R: Constitutive mobilization of CD34+ cells into the peripheral blood in idiopathic myelofibrosis may be due to the action of a number of proteases. Blood 2005, 105:4508-45I5.

49. Burgaleta C, Gonzalez N, Cesar J: Increased CD I I/CD I 8 expression and altered metabolic activity on polymorphonuclear leukocytes from patients with polycythemia vera and essential thrombocythemia. Acta Haematol 2002, 108:23-28.

50. Falanga A, Marchetti M, Evangelista $V$, Vignoli A, Licini M, Balicco M, Manarini S, Finazzi G, Cerletti C, Barbui T: Polymorphonuclear leukocyte activation and hemostasis in patients with essential thrombocythemia and polycythemia vera. Blood 2000, 96:426I-4266.

5I. Gadhoum SZ, Sackstein R: CDI 5 expression in human myeloid cell differentiation is regulated by sialidase activity. Nat Chem Biol 2008, 4:75I-757.
52. Derolf AR, Bjorklund E, Mazur J, Bjorkholm M, Porwit A: Expression patterns of CD33 and CDI5 predict outcome in patients with acute myeloid leukemia. Leuk Lymphoma 2008, 49:|279-|29|.

53. Gruss HJ, Kadin ME: Pathophysiology of Hodgkin's disease: functional and molecular aspects. Baillieres Clin Haematol 1996, 9:4I7-446.

54. Klippel S, Strunck E, Busse CE, Behringer D, Pahl HL: Biochemical characterization of PRV-I, a novel hematopoietic cell surface receptor, which is overexpressed in polycythemia rubra vera. Blood 2002, 100:244I-2448.

Publish with Bio Med Central and every scientist can read your work free of charge

"BioMed Central will be the most significant development for disseminating the results of biomedical research in our lifetime. "

Sir Paul Nurse, Cancer Research UK

Your research papers will be:

- available free of charge to the entire biomedical community

- peer reviewed and published immediately upon acceptance

- cited in PubMed and archived on PubMed Central

- yours - you keep the copyright 